Int. J. Dev. Biol. 49: 645-651 (2005)

doi: $10.1387 /$ ijdb.052046jc

\title{
Seed maturation: developing an intrusive phase to accom- plish a quiescent state
}

\author{
JESÚS VICENTE-CARBAJOSA* and PILAR CARBONERO \\ Laboratorio de Bioquímica y Biología Molecular, Departamento de Biotecnología-UPM, ETS Ingenieros Agrónomos, Madrid, Spain
}

\begin{abstract}
Plants, as sessile life forms, have evolved diverse mechanisms to circumvent unfavourable growth conditions, among them interruption of the life cycle is one of the most successful strategies. During seed formation, embryo development can proceed through a maturation phase that allows the entry into a quiescent state and represents an evolutionary advantage, since it facilitates dispersal and resuming of growth under optimal environmental conditions. In the maturation phase different gene expression programmes devoted to the accumulation of storage compounds, acquisition of desiccation tolerance and entry into quiescence occur, which are highly coordinated and under fine regulatory control. This paper is focused on recent findings related to central transcription factors which regulate gene expression during maturation. The structure of established regulatory networks is presented based on extensive gene promoter analyses and the characterisation of mutants affecting seed development and maturation. Different aspects of gene regulation both in the embryo and endosperm are covered and comparisons between monocot and dicot species on the basis of current knowledge of the system are also presented.
\end{abstract}

KEY WORDS: embryo, endosperm, seed development, quiescence, transcription factors

\section{Introduction}

Plants, as sessile life forms, have evolved diverse mechanisms to circumvent unfavourable growth conditions, among them interruption of the life cycle is one of the most successful strategies. Spermaphyta, or seed plants, are characterised by the formation of the seed, a structure originated from the fertilised ovule, that includes the embryo and other maternally derived tissues. Embryogenesis within the seed allows the entry into a quiescent state that represents an evolutionary advantage since it facilitates dispersal and resuming of growth under optimal environmental conditions. Seed formation is an intricate process that can be roughly divided into proper embryogenesis (cell division and morphogenesis), followed by a maturation phase, characterised by storage compound accumulation, acquisition of desiccation tolerance, growth arrest and the entry into a dormancy period of variable length that is broken upon germination (Harada, 1997). In essence, seed maturation involves all structures comprised within the seed, but predominantly the embryo and the endosperm originated by a double fertilisation event. Maturation leads to a developmental end-point in the endosperm, whereas the embryo retains the regenerating capacity after germination. Despite these differences, both embryo and endosperm share many features concerning the physiological changes and underlying molecular mecha- nisms associated with maturation.

In this review, we will re-examine minor aspects of seed maturation as a physiological process opposed to germination and will focus on recent findings related to central transcriptional regulators that participate in gene expression programmes associated with embryo and endosperm maturation. In the past, the study of seedspecific gene expression has led to the idea of different regulatory mechanisms in monocot- and dicotiledoneous species. However, a closer watch uncovers a limited perception, probably sustained on a knowledge biased from the different prevailing tissues in the seed of the two phylogenetic groups. Current data, clearly points to the participation of similar and sometimes the same factors in both organs. Moreover, new roles, out of the seed, have been discovered for regulators considered to be seed-specific and new functions within the seed assigned to previously known regulators unrelated to this organ. Altogether, these findings are enabling to perceive seed maturation as an "intrusive phase" in the developing embryo, similar to other phases introduced in the course of evolution at different times and in different taxa to produce growth arrest in a reversible manner (Harada, 1999; Kaplan et al., 1997).

Abbreviations used in this paper: bZIP, basic leucine zipper; DAF, days after flowering; DOF, Dna binding with One Finger; SSP, seed storage protein; TF, transcription factor.

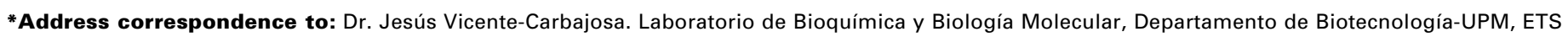
Ingenieros Agrónomos, 28040 Madrid, Spain. Fax: +34-91-336-5695. e-mail: jesus.vicente@upm.es
} 
In addition, extensive studies of regulatory networks are facilitating the identification of master regulators, responsible for the "seed fate", which directly participate in transcriptional control during maturation or modulate the activities of other factors acting under their influence.

\section{Physiology of seed maturation}

The maturation phase is started once the embryo and endosperm have completed the morphogenesis and patterning stages (Wobus et al., 1999). This phase is characterised by a growth arrest, followed by the synthesis and accumulation of reserves, whose degradation upon germination will provide nutrients to the growing seedling before the photosynthetic capacity is fully acquired (Baud et al., 2002). Early and mid phases of maturation are

A

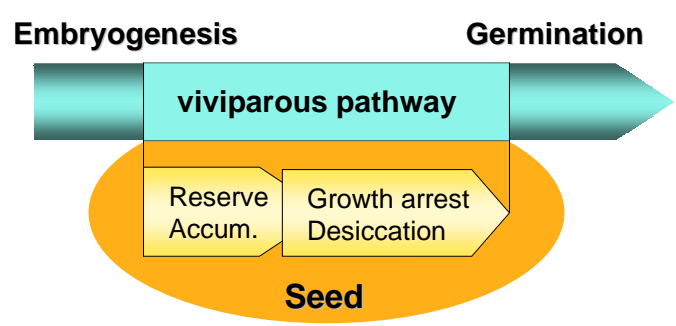

B

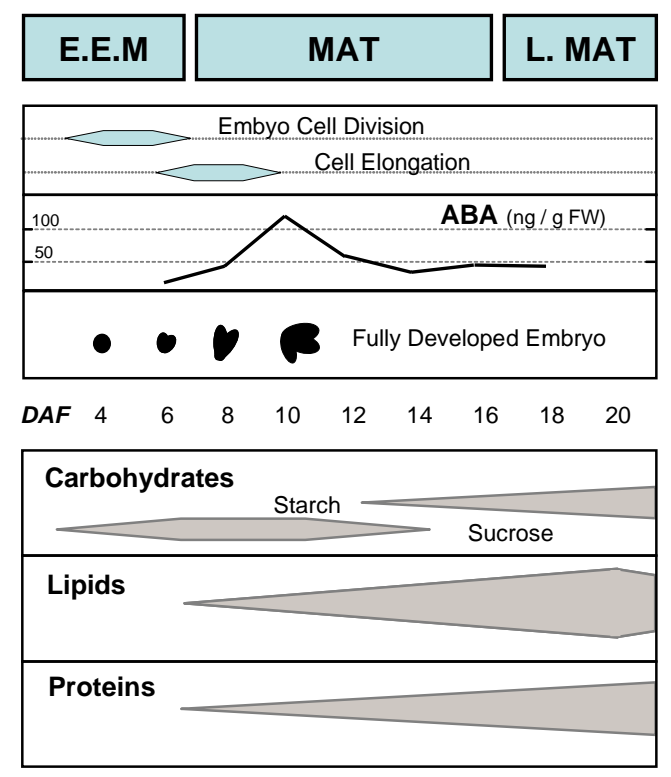

Fig. 1. Development within the seed. Phases and Features. (A) Representation of embryo development under a viviparous pathway or within the seed, undergoing typical maturation phases of reserve compound synthesis and accumulation, growth arrest, acquisition of desiccation tolerance and entry into quiescence. Germination is indicated as the exit point of development from the seed. (B) Time course of Arabidosis seed development (adapted from Baud et al., 2002), indicating major events during early embryo morphogenesis (E.E.M.), maturation (MAT) and late maturation (L.MAT) phases. Embryo globular, heart, torpedo and mature stages are represented in parallel to the $A B A$ levels and abundance of storage compound in the seed. dominated by the action of ABA, initially synthesised in the maternal tissues and later on, although to a lower extent, in the embryo and endosperm (Nambara et al., 2003). Transcription of major seed storage protein genes occurs mainly during this period. Subsequently, ABA levels decline and late maturation follows characterised by the synthesis of LEA (Late Embryogenesis Abundant) proteins, associated to the dehydration process and acquisition of desiccation tolerance. During this stage, accumulation of storage metabolites prevails in the form of carbohydrates (endosperm) or lipids (embryo), a quiescent state is accomplished and dormancy, the inability to grow under otherwise favourable conditions, can be established (Holdswoth et al., 1999).

Maturation is not an obligatory process and if embryos are removed from the seed and the ABA effects eliminated, they can proceed through the germination phase and develop into normal seedlings (see Figs. 1A, 4). In certain plants, like mangroves, embryogenesis proceeds directly to the seedling state. Similarly, so-called viviparous mutants in other plants display an analogous behaviour. In addition to ABA, other hormones are important in seed development, like auxins, cytokinins and gibberellins (GAs). In particular, the synthesis and requirement of active GAs during the maturation phase have been demonstrated in elegant experiments in maize embryos (White et al., 2000). It is now widely accepted that maturation is not determined by $A B A$ alone but instead by the ABA/GA balance.

Exciting results on metabolites as signals, as well as metabolism and accumulation of nutrients during seed development have been extensively covered in recent publications (Baud et al., 2002; Hills, 2004; Borisjuk et al., 2004) and are outside the scope of this review.

\section{Mutations affecting seed development}

Seed mutants have been an important source of information about the maturation phase both in monocot and dicot species. In cereals, due to the importance of the endosperm (the first world crop), seed mutants have been mostly seek on the basis of modifications in this organ. While this has resulted in the identification of important mutations affecting maturation outputs, many embryo mutants remain overlooked. In dicot species, e.g. Arabidopsis, a great number of seed developmental mutants display altered phenotypes on maturation features, but many of them are not specific to this phase. Instead, they are altered in basal activities required for normal embryo development with subsequent effects into the maturation phase (Tzafrir et al., 2004). In addition, certain mutants impaired in seed maturation show abnormal embryonic behaviour. Although this situation has initially made difficult to establish the boundaries between embryo development and maturation proper, it has enabled the identification of master genes that determine a state of competence under which maturation gene expression programmes occur.

\section{Gene expression programmes associated with seed maturation}

As previously described, physiological and metabolic conditions prevailing in the seed during the maturation phase lead to the accumulation of storage compounds and other products conferring desiccation tolerance. Accordingly, gene expression programmes 
Seed maturation

are primarily related to these processes. From early studies, it was known that most abundantly expressed genes in the seeds correspond to seed storage proteins, oleosins, LEA proteins and enzymes implicated in carbohydrate and lipid biosynthesis. Consequently, many of these genes have for a long time served as molecular markers, specific to this phase.

With the introduction of new high-throughput technologies, seed maturation has been investigated on a genome-scale basis. Transcriptome analysis has been performed in developing seeds of monocot and dicot species (Girke et al., 2000; Ruuska et al., 2002, Nakabayashi et al., 2004; Srenivalasu et al., 2002; Soeda et al., 2005) and allowed to identify new seed-specific genes, to redefine patterns of gene expression and to recognize new groups of co-regulated genes. The forthcoming years will probably see a great advance in the transcriptome analysis of seed mutants and the consequent deciphering of regulatory networks underlying seed maturation.

An important fact to point is that many of the final outputs of the maturation-induced gene expression programmes are common in monocot and dicot species, no matter if they occur in the embryo or in the endosperm. One such a case is a group of seed storage proteins ( $S S P$ ) genes, encoding specific dicot albumins and monocot prolamins, which can be evolutionary traced to a common ancestor. Gene promoter cis-acting motives and interacting transcription factors have been shown to be functionally exchangeable between both systems, indicating a remarkable conservation in the machinery responsible for the maturation gene expression programmes. In the following sections we will summarise the current knowledge of important regulatory sequences and interacting transcription factors present in these promoters, in the framework of known key regulators of seed development and seedspecific expression.

\section{Maturation regulatory elements in dicot species}

Regulatory cis-acting elements required for specific expression of $S S P$ genes have been determined (Ezcurra et al., 2000) in numerous dicot species and can be illustrated on the $2 \mathrm{~S}$ albumin/ napin gene promoters (see Fig. 2) Besides high sequence conservation, functional relevance of these elements has been demonstrated by site-specific mutagenesis and gain of function experiments. The best-characterised motives include the RY element, the ACGT box and the AACA motif, representing putative targets for B3, bZIP and MYB transcription factors, respectively.

Alternative strategies, like the analysis of mutants with altered features in the seed, have also led to the identification of genetic loci affecting the maturation programme. In Arabidopsis four loci: $\angle E C 1, \angle E C 2, F U S 3$ and $A B / 3$ are fundamental in the control of different aspects of seed development. LEC1 is a homologue of the CAAT binding factor HAP3 subunit (Lotan et al., 1998) and LEC2, FUS3 and ABI3 belong to the B3 family of transcription factors (Stone et al., 2001; Luerssen et al., 1998; Giraudat et al., 1994). In terms of phenotypic alterations FUS3, LEC1 and LEC2 belong to the Leafy Cotolyden (LEC) type (Meinke et al., 1994) and loss of function in any of them result in the display of leaf primordia features (e.g. trychome formation) in the cotyledons, precocious growth of root and apical meristem, alterations in anthocyanin and storage product accumulation and reduction in the establishment of desiccation tolerance and dormancy. Functions of these genes

\section{Monocots}

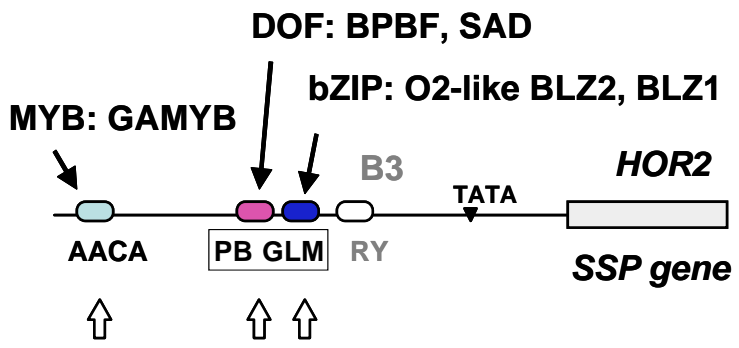

\section{Dicots}

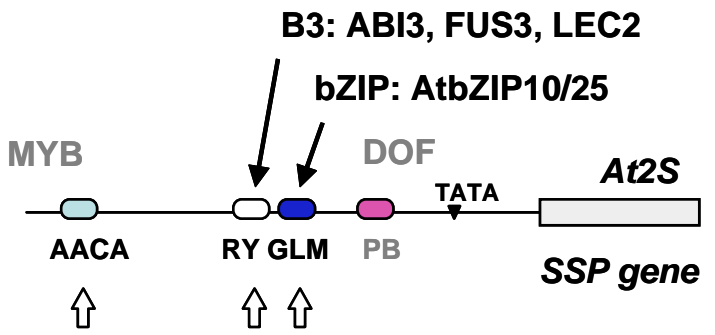

Fig. 2. Seed Storage Protein gene promoters: Regulatory elements and interacting factors. Scheme of the promoter structures of major seed storage protein genes, expressed during maturation in monocot and dicot species encoding for barley B-Hordein ( HOR2) and Arabidopsis $2 S$ albumin (At2S). Boxes represent conserved sequence motives found in homologous gene promoters. AACA, AACA box; PB, Prolamin Box; GLM, GCN4-Like Motif; RY, RY element. The boxed PB-GLM represents the Endosperm Box. Block arrows indicate functionally relevant boxes, assayed in mutation analyses. Potential DNA binding domains able to interact with the corresponding boxes are indicated. Transcription factors of recognised participation in the regulation through a particular box are shown and linked with arrows.

are not completely redundant, acting in an overlapping manner. Although structurally related to FUS3 and LEC3, ABI3 is not considered of the LEC type and loss of its function results in a failure to degrade chlorophyll, altered storage product accumulation, loss of desiccation tolerance and dormancy and ABA insensitivity upon germination (Fig. 3).

Mutations in any of these four regulators impaired the maturation programme and shift embryo development towards germination. Recently, exciting results have been obtained concerning their mode of action. The McCourt's group has described the ability to fully complement a fus3-3 loss-of-function mutant by expressing the FUS3 protein in the protodermal tissue of the embryo. Anthocyanin and trichome production in the fus 3 mutant requires the product of the TTG1 gene and the authors show that FUS3 is a negative regulator of TTG1 mRNA in the protodermal tissue. In addition, restoration of SSP accumulation was shown in the same complemented mutant and a similar effect displayed in the fus3-3/ ttg1 double mutant (Tsuchiya et al., 2004). However, the $t$ tg 1 mutation could not rescue other fus 3 -impaired functions, like desiccation tolerance and dormancy, indicating that FUS3 action 
occurs only partially through the TTG1 product. Up-regulation of FUS3 by auxins in the embryo was also demonstrated and the positive and negative regulation of $A B A$ and GA synthesis by FUS3, acting as a nexus of hormone action during embryogenesis (Gazzarrini et al., 2004; Curuba et al., 2004) Moreover, accumulation of SSPs in parenchyma cells of adult leaves miss-expressing FUS3 in the epidermis suggests a cell-nonautonomous mechanism in its mode of action. Other investigations have disclosed a positive regulation of LEC1 over FUS3 and $\mathrm{ABI} 3$ and their activation of SSP genes in a hierachical manner (Kagaya et al., 2005). Complex genetic and molecular interactions have been uncovered among these factors (Parcy et al., 1997 and personal communication) and deserve further examination.

In addition to the general "seed-competence" state generated by these factors, it has been demonstrated that they can particularly act through direct interactions with regulatory elements present in the promoters of output genes of the maturation phase. Functional assays for LEC2, FUS3 and ABI3 have corroborated such mechanisms on the RY element of different SSP gene promoters (Kroj et al., 2003; Reidt et al., 2002; Monke et al., 2004). Nevertheless, the action of these factors is a necessary but not sufficient requisite for the expression of the target genes, since mutations affecting other critical elements or their interacting factors, result in a poor (or absent) expression (Ezcurra et al., 2000). In this respect, the ACGT boxes as putative binding elements of bZIP proteins are reported targets of AtbZIP10 and 25 in SSP promoters and of ABI5 in $E m$ promoters, in both cases in concerted interaction with $A B I 3$ (Lara et al., 2003). Contribution of other elements, like AACA boxes, is known to be critical as well, although the interacting factors have not been identified yet. It is worth mentioning the high

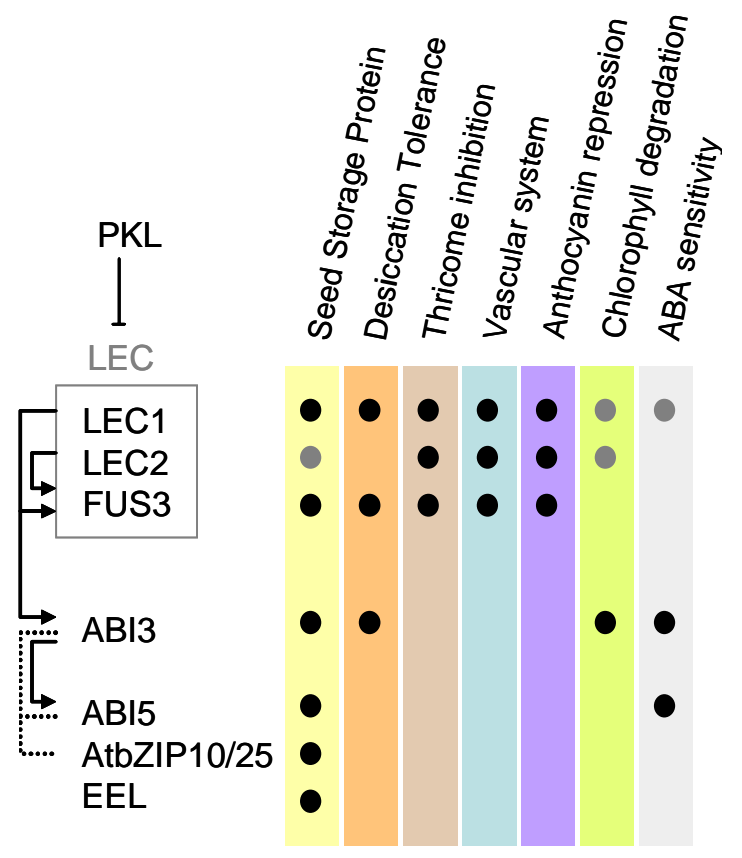

Fig. 3. Key regulatory genes identified in Arabidopsis thaliana affecting important traits of the maturation phase during seed development. The contribution of the different genes to diverse aspects of seed development is indicated by dots in each particular case. Arrows show the activating or repressing relationships disclosed among them and dotted lines represent reported protein-protein interactions. level of conservation, both in sequence and functionality, detected among different gene promoters in monocot and dicot species (Fig. 2) that encourages for the isolation of similar factors to those previously characterised in the alternative group.

\section{Maturation regulatory elements in monocot species}

Seed maturation has been extensively studied in cereal species, due to the importance of the endosperm as the major food and feed tissue in agriculture. The cereal endosperm is structured into different cellular domains comprising the aleurone, the starchy endosperm, embryo surrounding tissues and transfer cells (Olsen, 2004). The starchy endosperm is the principal storage tissue, where carbohydrates and SSP are accumulated during the maturation phase. Among the numerous known mutants affecting endosperm traits, many are altered in the pigmentation of the outer aleurone layer or the deposition of reserves in the starchy endosperm. Cereal SSP genes are among the first plant genes characterised and functionally studied. The bipartite endosperm box and the AACA motif are important regulatory elements (Takaiwa et al., 1996), repeatedly found in the promoters of SSP genes (see the model Bhordein gene promoter in Fig. 2). These cis-elements are bound by TFs of the bZIP, DOF and R2R3MYB classes including BPBF and SAD Dof proteins, OPAQUE2-like bZIP proteins BLZ2 and BLZ1 and R2R3MYB factor GAMYB (Vicente-Carbajosa et al., 1997; Mena etal., 1998; Vicente-Carbajosa etal., 1998; Oñate etal., 1999; Diaz et al., 2002; Diaz et al., 2005). Full activation is achieved by the synergistic effect of different TF combinations, suggesting that they are part of a regulatory complex. In support, protein-protein interactions have been detected among them. Although conserved RY elements are also present in the promoters of these genes, direct regulation by a B3-type transcription factor has not been reported so far. Nevertheless, it is worth mentioning that the VP1 gene (the monocot orthologue of $A B I 3$ ) is weakly expressed in the starchy endosperm, while highly expressed in the aleurone and embryo during the maturation phase, where it participates in the activation of LEA genes in an ABA dependent manner.

It is also remarkable that key factors participating in maturation programmes in the cereal endosperm, like GAMYB, BPBF or SAD, are also essential regulators in the post-germination phase (Gubler et al., 1995; Isabel-Lamoneda et al., 2003). Consistent with a mode of action based on exchangeable regulatory complexes under the influence of external TFs, this represents an example of how regulators can be recruited to perform different tasks depending on the context. In the seed framework, GAMYB, BPBF and SAD different actions are mediated by VP1 modulation (our unpublished results)

Maturation phase changes induced in the embryo of monocot seeds have been studied to a lesser extent, but strong similarities to the situation in the dicot embryo exists, like the well-known participation of VP1 in the regulation of $\angle E A$ and globulin SSP genes and the conserved interactions with bZIP orthologous to ABI5 factors (Hobo et al., 1999; Nakamura et al., 2001).

\section{Modules, overlaps and hierarchies in the structure of seed maturation programmes}

Maturation within the seed is a multipart process that affects both the embryo and the endosperm, leading through sequential steps 


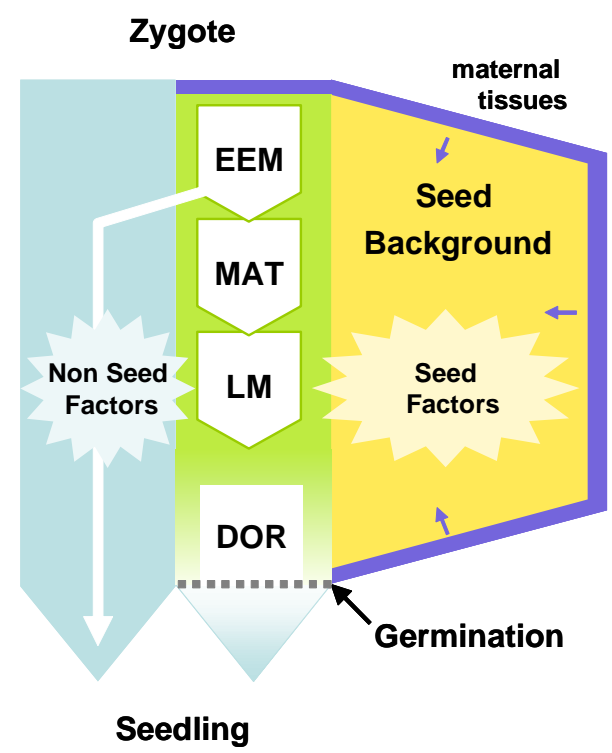

Fig. 4. Interactions in seed development and the establishment of seed maturation programmes. The progression of zygote development into a seedling in a seed and non-seed background is represented. Early embryogenesis and morphogenesis (EEM) events are common, but under a seed background the maturation programme is initiated. Following maturation (MAT) and late maturation (LM) events, a period of dormancy (DOR) can be sustained. When dormancy is broken and germination occurs, development proceeds out of the seed background. Seed factors, including maternally derived effects, are determinants of maturation and modulate de action of non-seed factors (see text for discussion).

into quiescence. As a whole, it can be divided into overlapping programmes of gene expression to accomplish different tasks, like synthesis of storage compounds, acquisition of desiccation tolerance or the establishment of dormancy. For a process with such a modular structure it is not surprising to discover that individual tasks might be implemented in different parts of the plant with functions unrelated to the seed. For instance, many of the genes related to desiccation tolerance can be induced in other organs under certain stress conditions (Bartels et al., 2001).

Furthermore, mutant analyses have allowed the identification of individual regulators that operate over a wide range of modules (or gene expression programmes) and that are therefore considered "master regulators" of the process (e.g. $\angle E C$ genes). Individual switching on of these genes results in the definition of a "seedcompetent" state that affects a precise set of tasks of the maturation phase, which are globally controlled by these factors in an overlapping, rather than a hierarchical manner. On top, at a different level of regulation, it has been shown in Arabidopsis that the master $\angle E C$ genes are repressed outside the embryo by the CHD3-chromatin-remodeling factor PICKLE (Dean Rider et al., 1999; see Fig. 3).

\section{Driving the maturation programme out of the seed}

Taking into account the described organisation of the maturation programme, it is conceivable to execute independent parts by manipulating selected regulators. In fact, different reports have shown that miss-expression of particular regulators can turn on precise expression programmes of seed maturation (Gazarrini et al., 2004; Kagaya etal., 2005) out of the seed. An interesting finding was the discovery of an ABI3-factor, initially thought to be a seedspecific regulator, as an important player in the induction of dormancy in buds (Horvath. etal., 2003). Like specific programmes of seed maturation, this process is associated to the growth inhibitory action of $A B A$, in which $A B I 3$ is known to be implicated. Again, this supports the idea of maturation being ancillary or intrusive to embryo development and points towards possible mechanisms that could make it rise, with subsequent evolutionary advantages.

\section{Remaining questions}

In recent years, important contributions have been made in different aspects of seed maturation, like studies on metabolism of storage compounds, identification of key regulatory elements or transcriptome analyses of the process at a whole-genome scale.

The identification of key regulatory transcription factors involved in the process allows addressing important and still opened questions. It remains unclear to what extent these key regulators are conserved in the different phylogenetic groups, for instance there is no evidence yet for a role of LEC genes in seed maturation of monocot species. Although conservation in the regulatory network that controls SSP is remarkable, extensive studies must be performed to provide information on other regulatory networks operating under the maturation programme to allow further comparisons. In particular, information concerning expression programmes in the dicot endosperm, or associated with the establishment of dormancy is still very limited.

Another key and recurrent issue in seed biology are the differences between embryo and endosperm, linked to the still controversial origin of the later (Berger, 2003). Involvement of key regulators of maturation programmes is significantly similar in the embryo and endosperm aleurone. A deeper knowledge of maturation in both systems and the influence of maternal and dosage effects (Dilkes et al., 2004) can shed new light into this question.

\section{Acknowledgments}

The authors would like to acknowledge the contribution of all members in our laboratory that generated many of the data discussed in this review. We are also grateful to Francois Parcy for sharing unpublished results and encouraging discussions. This work was funded by CAM 07B/0011/2002 (Spain), GEN2003-20859-C03-01/INTER MEC (Spain) and BMC 20036345 MCYT (Spain).

\section{References}

BARTELS D, SALAMINI F. (2001) Desiccation tolerance in the resurrection plant Craterostigma plantagineum. A contribution to the study of drought tolerance at the molecular level. Plant Physiol. 127(4):1346-53

BAUD S, BOUTIN JP, MIQUEL M, LEPINIEZ L, ROCHAT C. (2002). An integrated overview of seeddevelopment in Arabidopsis thaliana ecotype WS. Plant Physiol. Biochem. 40:151-160

BERGER F. (2003). Endosperm: the crossroad of seed development. Curr Opin Plant Biol. 6(1):42-50.

BORISJUK L, ROLLETSCHEK H, RADCHUK R, WESCHKE W, WOBUS U, WEBER H. (2004). Seed development and differentiation: a role for metabolic regulation. Plant Biol (Stuttg). 6(4):375-86.

CURABA J, MORITZ T, BLERVAQUE R, PARCY F, RAZ V, HERZOG M, VACHON G. (2004) AtGA3ox2, a key gene responsible for bioactive gibberellin biosynthesis, is regulated during embryogenesis by LEAFY COTYLEDON2 and FUSCA3 
in Arabidopsis. Plant Physiol. 136(3):3660-9.

DEAN RIDER S JR, HENDERSON JT, JEROME RE, EDENBERG HJ, ROMEROSEVERSON J, OGAS J. (2003) Coordinate repression of regulators of embryonic identity by PICKLE during germination in Arabidopsis. Plant J. 35(1):33-43.

DIAZI, VICENTE-CARBAJOSAJ, ABRAHAMZ, MARTINEZM, ISABEL-LA MONEDA I, CARBONERO P. (2002). The GAMYB protein from barley interacts with the DOF transcription factor BPBF and activates endosperm-specific genes during seed development. Plant J. 29(4):453-64.

DIAZ I, MARTINEZ M, ISABEL-LAMONEDA I, RUBIO-SOMOZA I, CARBONERO, P (2005) The DOF protein, SAD, interacts with GAMYB in plant nuclei and activates transcription of endosperm-specific genes during barley seed development. Plant J. 42:652-62.

DILKES BP, COMAI L. (2004) A differential dosage hypothesis for parental effects in seed development. Plant Cel/16(12):3174-80.

EZCURRA I, WYCLIFFE P, NEHLIN L, ELLERSTROM M, RASK L. (2000) Transactivation of the Brassica napus napin promoter by $A B I 3$ requires interaction of the conserved $\mathrm{B} 2$ and $\mathrm{B} 3$ domains of $\mathrm{ABI} 3$ with different cis-elements: B2 mediates activation through an ABRE, whereas B3 interacts with an RY/G-box. Plant J. 24(1):57-66.

GAZZARRINI S, TSUCHIYA Y, LUMBA S, OKAMOTO M, MCCOURT P. (2004) The transcription factor FUSCA3 controls developmental timing in Arabidopsis through the hormones gibberellin and abscisic acid.Dev Cell. 7(3):373-85.

GIRAUDAT J, HAUGE BM, VALON C, SMALLE J, PARCY F, GOODMAN HM. (1992) Isolation of the Arabidopsis ABI3 gene by positional cloning. Plant Cell. 4(10):125161

GIRKE T, TODD J, RUUSKA S, WHITE J, BENNING C, OHLROGGE J. (2000) Microarray analysis of developing Arabidopsis seeds. Plant Physiol. 124(4):157081.

GUBLER F, KALLA R, ROBERTS JK, JACOBSEN JV. (1995) Gibberellin-regulated expression of a myb gene in barley aleurone cells: evidence for Myb transactivation of a high-pl alpha-amylase gene promoter. Plant Cel/7(11):1879-91.

HARADA JJ. (1997) Seed maturation and control of germination. In Cellular and Molecular Biology of Plant Seed Development. Edited by Larkins BA, Vasil IK. Dordrecht: Kluwer Academic Publishers 545-592.

HARADA, J.J. (1999) Signaling in plant embryogenesis. Curr Opin Plant Biol. 2(1): p. 23-7.

HILLS, M. J. (2004). Control of storage-product synthesis in seeds. Curr Opin Plant $\mathrm{BiO} / 7(3):$ 302-8.

HOBO T, KOWYAMA Y, HATTORIT. (1999) A bZIP factor, TRAB1, interacts with VP1 and mediates abscisic acid-induced transcription. Proc Natl Acad Sci USA. 96(26):15348-53.

HOLDSWORTH M, KURUP S, MCKIBBIN R. (1994) Molecular and genetic mechanisms regulating the transition from embryo development to germination. Trends Plant Sci. 4(7):275-280

HORVATH DP ANDERSON JV, CHAO WS, FOLEY ME (2003). Knowing when to grow: signals regulating bud dormancy. Trends Plant Sci. 8(11):534-40. Review. Erratum in: Trends Plant Sci. 2004 9(1):12.

ISABEL-LAMONEDA I, DIAZ I, MARTINEZ M, MENA M, CARBONERO P. (2003) SAD: a new DOF protein from barley that activates transcription of a cathepsin $B$ like thiol protease gene in the aleurone of germinating seeds. Plant J. 33(2):32940.

KAGAYA Y, OKUDA R, BAN A, TOYOSHIMA R, TSUTSUMIDA K, USUI H, YAMAMOTO A,HATTORI T. (2005) Indirect ABA-Dependent Regulation of Seed Storage Protein Genes by FUSCA3 Transcription Factor in Arabidopsis. Plant Cel/ Physiol. 2

KAGAYA Y, TOYOSHIMA R, OKUDA R, USUIH, YAMAMOTO A, HATTORIT (2005). LEAFY COTYLEDON1 Controls Seed Storage Protein Genes through Its Regulation of FUSCA3 and ABSCISIC ACID INSENSITIVE3. Plant Cell Physiol. 46: 300-311.

KAPLAN DR, COOKE TJ (1997) Fundamental concepts in the embryogenesis of dicotyledons: a morphological interpretation of embryo mutants. Plant Cel/9:19031919.

KROJ T, SAVINO G, VALON C, GIRAUDAT J, PARCY F. (2003) Regulation of storage protein gene expression in Arabidopsis. Development 130(24):6065-73.

LARA P, ONATE-SANCHEZ L, ABRAHAM Z, FERRANDIZ C, DIAZI, CARBONERO $P$, VICENTE-CARBAJOSA J. (2003) Synergistic activation of seed storage protein gene expression in Arabidopsis by $\mathrm{ABI} 3$ and two bZIPs related to OPAQUE2. J Biol Chem. 278(23):21003-11

LOTAN T, OHTO M, YEE KM, WEST MA, LO R, KWONG RW, YAMAGISHI K, FISCHER RL, GOLDBERG RB, HARADA JJ. (1998) Arabidopsis LEAFY COTYLEDON1 is sufficient to induce embryo development invegetative cells. Cell 93(7):1195-205

LUERSSEN H, KIRIK V, HERRMANN P, MISERA S. (1998) FUSCA3 encodes a protein with a conserved VP1/AB13-like B3 domain which is of functional importance for the regulation of seed maturation in Arabidopsis thaliana. Plant $\mathrm{J}$. 15(6):755-64.

MEINKE DW, FRANZMANN LH, NICKLE TC, YEUNG EC. (1994) Leafy Cotyledon Mutants of Arabidopsis. Plant Cell. 6(8):1049-1064.

MENA M, VICENTE-CARBAJOSA J, SCHMIDT R, CARBONERO P (1998) An endosperm-specific DOF protein from barley, highly conserved in wheat, binds to and activates transcription from the prolamin-box of a native B-hordein promoter in barley endosperm. Plant J. 16: 53-62.

MONKE G, ALTSCHMIED L, TEWES A, REIDT W, MOCK HP, BAUMLEIN H, CONRAD U. (2004) Seed-specific transcription factors ABI3 and FUS3: molecular interaction with DNA. Planta. 219(1):158-66.

NAKABAYASHI K, OKAMOTO M, KOSHIBA T, KAMIYA Y, NAMBARA E (2005). Genome-wide profiling of stored $m R N A$ in Arabidopsis thaliana seed germination: epigenetic and genetic regulation of transcription in seed. Plant J. 41(5):697-709.

NAKAMURA S, LYNCH TJ, FINKELSTEIN RR. (2001) Physical interactions between ABA response loci of Arabidopsis. Plant J. 26(6):627-35.

NAMBARA E, MARION-POLLA. (2003) ABA action and interactions in seeds. Trends Plant SCi. 8(5):213-7.

OLSEN OA. (2004) Nuclear endosperm development in cereals and Arabidopsis thaliana. Plant Cell. 16 Suppl:S214-27.

ONATE L, VICENTE-CARBAJOSA J, LARA P, DIAZ I, CARBONERO P. (1999) Barley BLZ2, a seed-specific bZIP protein that interacts with BLZ1 in vivo and activates transcription from the GCN4-like motif of B-hordein promoters in barley endosperm. J Biol Chem. 274(14):9175-82.

PARCY F, VALON C, KOHARA A, MISERA S, GIRAUDAT J. (1997) The ABSCISIC ACID-INSENSITIVE3, FUSCA3 and LEAFY COTYLEDON1 loci act in concert to control multiple aspects of Arabidopsis seed development. Plant Cell. 9(8):126577.

REIDT W, WOHLFARTH T, ELLERSTROM M, CZIHAL A, TEWES A, EZCURRA I, RASK L, BAUMLEIN H. (2000) Gene regulation during late embryogenesis: the RY motif of maturation-specific gene promoters is a direct target of the FUS3 gene product. Plant J. 21(5):401-8.

RUUSKA SA, GIRKE T, BENNING C, OHLROGGE JB. (2002). Contrapuntal networks of gene expression during Arabidopsis seed filling. Plant Cell. 14(6):1191206.

SOEDA Y, KONINGS MC, VORST O, VAN HOUWELINGEN AM, STOOPEN GM, MALIEPAARD CA, KODDE J, BINO RJ, GROOT SP, VAN DER GEEST AH. (2005). Gene Expression Programs during Brassica oleracea Seed Maturation, Osmopriming and Germination Are Indicators of Progression of the Germination Process and the Stress Tolerance Level. Plant Physiol. 137(1):354-68.

SREENIVASULU N, ALTSCHMIED L, PANITZ R, HAHNEL U, MICHALEK W, WESCHKE W,WOBUS U. (2002). Identification of genes specifically expressed in maternal and filial tissuesof barley caryopses: a cDNA array analysis. Mo/Genet Genomics. 266(5):758-67.

STONE SL, KWONG LW, YEE KM, PELLETIER J, LEPINIEC L, FISCHER RL, GOLDBERG RB, HARADA JJ. (2001). LEAFY COTYLEDON2 encodes a B3 domain transcription factor that induces embryo development. Proc Nat/Acad SCi USA. 98(20):11806-11.

TAKAIWA F, YAMANOUCHIU, YOSHIHARA T, WASHIDA H, TANABE F., KATO A, YAMADA K. (1996). Characterization of common cis-regulatory elements responsible for endosperm-specific expression of members of the rice glutelin multigene family. Plant Mol. Biol. 30: 1207-1221.

TSUCHIYA Y, NAMBARA E, NAITO S, MCCOURT P. (2004). The FUS3 transcription factor functions through the epidermal regulator TTG1 during embryogenesis in Arabidopsis. Plant J. 37(1):73-81.

TZAFRIRI, PENA-MURALLAR, DICKERMANA, BERGM, ROGERS R, HUTCHENS S, SWEENEY TC, MCELVER J, AUX G, PATTON D, MEINKE D. (2004). Identification of genes required for embryo development in Arabidopsis. Plant 
Physiol. 135(3):1206-20.

VICENTE-CARBAJOSA J, MOOSE SP, PARSONS RL, SCHMIDT RJ. (1997). A maize zinc-finger protein binds the prolamin box in zein gene promoters and interacts with the basic leucine zipper transcriptional activator Opaque2. ProcNat/ Acad Sci USA. 94(14):7685-90.

VICENTE-CARBAJOSA J, ONATE L, LARA P, DIAZ I, CARBONERO P. (1998). Barley BLZ1: a bZIP transcriptional activator that interacts with endospermspecific gene promoters. Plant J. 13(5):629-40.
WHITE CN, RIVIN CJ. (2000). Gibberellins and seed development in maize. II. Gibberellin synthesis inhibition enhances abscisic acid signaling in cultured embryos. Plant Physiol. 122(4):1089-97.

WHITE CN, PROEBSTING WM, HEDDEN P, RIVIN CJ. (2000) Gibberellins and seed development in maize. I. Evidence that gibberellin/abscisic acid balance governs germination versus maturation pathways. Plant Physiol.122: 1081-1088.

WOBUS U, WEBER H. (1999). Seed maturation: genetic programmes and control signals. Curr Opin Plant Biol. 2(1):33-8. 